\title{
Education, Role, and Prospects of Advanced Practice Nurses in Hospice and Palliative Care in South Korea
}

\author{
So-Hi Kwon, R.N., A.P.N., Ph.D., Myung-Hee Park, R.N., A.P.N., Ph.D.* and \\ Hyun Sook Kim, R.N., A.P.N., Ph.D.' \\ College of Nursing, Research Institute of Nursing Science, Kyungpook National University, Daegu, \\ *Hospice \& Palliative Center, Seoul St. Mary's Hospital, The Catholic University of Korea, Seoul, \\ ${ }^{\dagger}$ Department of Nursing, Korea National University of Transportation, Jeungpyeong, Korea
}

Hospice palliative care refers to holistic care provided by an interdisciplinary team aimed at improving the quality of life of patients suffering from life-threatening diseases and their families. Among interdisciplinary team members, hospice advanced practice nurses (APNs) trained as master's-level advanced nursing professionals are leaders who play an important role in providing patient-centered care and improving the quality of services. The Medical Service Act revised in 2018 requires the scope of practice of APNs in each field to be specified in the Ordinance of the Ministry of Health and Welfare. Accordingly, discussions on the role and scope of practice of hospice APNs are actively underway. In this review, the curriculum of hospice APNs, their work responsibilities and roles, and their current status are reviewed, and the future direction of the hospice APN system is also discussed.

Key Words: Hospice and palliative care nursing, Advanced practice nursing, Education, Nurse's role
Received January 14, 2021

Revised January 21, 2021

Accepted January 23, 2021

\author{
Correspondence to \\ Hyun Sook Kim \\ ORCID: \\ https://orcid.org/0000-0001-7108-0966 \\ E-mail: hyunsookkim@ut.ac.kr
}

This was supported by Korea National University of Transportation in 2020.

\section{INTRODUCTION}

High-quality end-of-life care is considered to be a basic human right. To successfully integrate hospice palliative care (HPC) into the healthcare system, a stepwise model of care in a pyramidal structure has been widely adopted in recent years [1]: namely, (a) HPC approach in all settings; (b) primary HPC for all patients who have life-threatening illnesses; and (c) specialized HPC provided by an interdisciplinary HPC team. Hospice advanced practice nurses (APNs) serve as core members of the interdisciplinary team at the top of this stepwise HPC delivery system, and they provide HPC to terminal patients and their families who have complex care needs. Hospice APNs, with master's degree-level education and national cer- tification, serve as leaders in HPC; they are important human resources to reinforce and improve general HPC and primary hospice care services. Therefore, to establish strategies for the development of HPC, it is necessary to reassess institutional support and policy directions regarding how to educate APNs, how many APNs to produce, and what roles to assign APNs.

Among the HPC interdisciplinary team members, nurses serve as the foundation in providing quality care that integrates physical, psychological, spiritual, and social care [2]. The Act on Hospice and Palliative Care and Decisions on LifeSustaining Treatment for Patients at the End of Life enforced in August 2017 (hereinafter referred to as the Act on Decisions on Life-Sustaining Treatment) [3], placed the highest priority on establishing the infrastructure to properly care for end- 
of-life patients. The Act became a springboard to elevate the standards of HPC in South Korea, and now hospice APNs both provide patient care and serve as team coordinators, enhancing their role in the field of HPC [4].

In South Korea, APNs are trained to become field specialists in 13 areas: public health, nurse anesthesia, home care, psychiatric nursing, infection control, health and safety, emergency nursing, gerontological nursing, critical care, hospice care, oncological nursing, clinical nursing, and pediatric nursing. Since the first Korean APN certification examination in 2005, the total number of APNs has reached 15,718, and hospice APNs began to be trained in 2006, reaching 582 by December, 2019 [5]. From the beginning, the Korean APN system, unlike those of other nations (e.g., the United States, Japan, and Taiwan), has legally specified titles, qualifications, and a consistent APN educational curriculum, actively fostering APNs. However, despite the increased demand of nurses who play the role of APNs in clinical settings, the number of APNs who work as APNs with certification has been steadily decreasing. The largest cause of this paradoxical phenomenon is the lack of institutional support; for example, (a) there have been repeated controversies over unlicensed medical practice due to the absence of legal grounds for the scope of practice (SOP); and (b) no reimbursement from national healthcare insurance for specialized care provided by APNs [5-7]. Accordingly, in March 2018, an amendment (Article 78 of the Medical Service Act) was published, which provides legal ground to specify APNs' SOP, and it was enforced starting on March 28, 2020 [8]. Subordinate statutes, however, were not established, which means that the SOP for APNs is not yet legally defined. In hospice palliative care, it is needed to distinguish between hospice APNs and general hospice palliative nurses and to define their roles clearly. When duties are not clearly defined, conflict or overlap in roles could occur, which may hinder the provision of systematic nursing care services.

Accordingly, it is necessary to review the current state of hospice APNs' training and their duties and to identify effective strategies that would assist hospice APNs, could fully use their capabilities and provide quality care. As an effort to vitalize the Korean hospice APN system, this study aims to (a) review hospice APNs' educational curriculum, (b) suggest hospice APNs' roles and SOP by reviewing domestic and international statutes and studies, and (c) discuss their prospects.

\section{MAIN BODY}

\section{Hospice APN education in South Korea}

\section{1) Definition of hospice APNs}

Based on the Medical Service Act of 1973, APNs in South Korea were first defined as "specialized nurses", referring to nurses in three specialized areas: public health, anesthesiology, and psychiatry. The official term was changed to "advanced practice nurse (APN)" in the amendment of Medical Service Act in 2000, and as the category of home care APNs was added, the foundation for APNs was established. Six more specialized areas, including hospice care, were added to the categories in 2003 and three more areas were added in 2006, resulting in the 13 current APN areas [4]. The Korean Accreditation Board of Nursing Education (KABONE) defines APNs as professionals with a high level of knowledge and skills, who provide advanced nursing care to patients and their families in medical institutions and local communities [9].

According to the "Regulations regarding qualification recognition of professional nurses" [10] in the Medical Service Act, hospice APNs are defined as follows: (a) those who are licensed and have 3 years or more of experience in nursing practice in the relevant field within the last 10 years; (b) those who have completed the APN course at a graduate school designated by the Ministry of Health and Welfare; (c) those who passed the Korean APN Licensing Examination conducted by KABONE with the commission of the Ministry of Health and Welfare; and (d) those who were certified as foreign-licensed APNs. The Act on Decisions on Life-Sustaining Treatment defines hospice as the medical service that provides comprehensive assessment and treatment to terminal patients (e.g., those diagnosed with cancer, acquired immunodeficiency syndrome, chronic obstructive pulmonary disease, or chronic liver disease) or terminal patients and their families in physical, psychosocial, and spiritual areas, including pain and symptom relief [3].

In short, hospice APNs can be defined as professionals, who provide advanced level nursing that includes comprehensive assessment of physical, psychosocial, and spiritual areas, pain 
relief, and symptoms relief, to improve the quality of life of terminal and end-of-life patients and their families.

\section{2) Hospice APN education curriculum and educational institution}

In order to become a hospice APN, one must complete a master's degree program at an APN educational institution designated by the Ministry of Health and Welfare. To be admitted to a hospice APN program, it is required to have 3 years or more of professional nursing experience in the relevant field within the last 10 years. As of January 2021, 10 universities are designated as hospice APN educational institutions with an annual admission quota of 75 students. However, only $62.7 \%$ of available slots for students at the APN educational institutions are filled (Table 1) [5]. The students are distributed across geographical areas as follows: 25 in Seoul, 5 in Daejeon, 15 in Daegu, 15 in Busan, and 15 in Changwon, Gyeongnam Province. This low registration rate and regional imbalance may stand as a significant obstacle in establishing an effective policy regarding supply and demand of the APN workforce.

The Ministry of Health and Welfare entrusts the KABONE with managing APN education and the licensing examination. The KABONE requires APN candidates to complete 10 credit hours of field-related theories and 10 credit hours (minimum 300 hours) of clinical practicum in each field as part of the standard educational curriculum for APNs. Common mandatory coursework across APN programs includes pathophysiol- ogy, pharmacology, advanced health assessment, nursing theory, nursing research, and roles and policy regarding APNs [9]. The hospice APN curriculum includes 10 credit hour specialty course subjects, encompassing an introduction to hospice palliative nursing, pain and symptom management nursing, psychosocial and spiritual nursing, counseling and bereavement care, and hospice palliative nursing administration. Along with 300 hours of clinical practicum, the total number of credit hours required to complete the hospice APN coursework is 33 or more. This requirement is over-demanding compared with the 24 or 27 credit hours required for general graduate school masters' degree coursework from other disciplines. In addition, students who enrolled in APN training at general graduate schools need to write a thesis to obtain the masters' degree. The absence of financial compensation provided to APNs, and the intense academic burden required to become an APN, could lower the desire to take courses to become hospice APNs.

Nurses can apply for the APN Licensing Examination if (a) they have completed the APN coursework, or if (b) they hold an APNs' license approved by KABONE. To pass the test, one must score $60 \%$ or higher on the written test and the practical test. The first-stage written test is composed of 150 multiplechoice questions with five choices, and the second-stage practical test is composed of open-ended questions regarding clinical cases [9]. The passing rates for the 16th APN Licensing examination in 2019 were $93.3 \%$ for the first test and $93.1 \%$

Table 1. Status of Educational Institutions of Hospice APNs.

\begin{tabular}{lcc}
\multicolumn{1}{c}{ University } & $\begin{array}{c}\text { Designated year for } \\
\text { starting education }\end{array}$ & Admission quota \\
\hline Catholic University of Korea, Graduate School of Clinical Nursing Science & 2004 & 10 \\
Kyungpook National University, Graduate School of Nursing & 2004 & 5 \\
Keimyung University, Graduate School of Nursing & 2005 & 5 \\
Kosin University, Graduate School of Nursing & 2005 & 5 \\
Daegu Catholic University, Graduate School of Medical and Health Industry & 2005 & 5 \\
Catholic University of Pusan, Graduate School of Nursing & 2004 & 10 \\
Ewha Womans University, Graduate School of Clinical Biohealth & 2004 & 5 \\
Chonnam National University, Graduate School of Nursing & 2004 & - \\
Changshin University, Graduate School of Nursing & 2018 & 15 \\
Chungnam National University, Graduate School of Nursing & 2004 & 5 \\
Hanyang University, Graduate School of Clinical Nursing & 2005 & 10 \\
Total & & 75 \\
\hline
\end{tabular}

APNs: advanced practice nurses. 
for the second test. The final passing rate was 84.4\% [5].

\section{3) Training and activity of hospice APNs}

The educational curriculum for hospice APNs was first introduced in 2004. From 2006 to December 2019, this curriculum has produced 582 hospice APNs. This number accounts for $3.7 \%$ of the total number $(15,718)$ of APNs across 13 areas. According to a survey conducted by the Korean Nursing Association in 2014, to which 65\% of the licensed APNs responded, only $22 \%$ of the licensed APNs were actually working in a field that matched their qualifications [11]. The Hospital Nurses Association's recent survey on the status of hospital nursing staff placement also revealed that only 683 out of 15,300 licensed APNs were working in hospitals in 2018 [12]. These findings indicate that most APNs are not working in a field that matches their qualifications. The reasons are multi-faceted and complex. From the perspective of an APN, the motivation for obtaining an APN license may be due to future growth or possible opportunities in their career development, rather than reinforcing one's performance competencies in one's current department. A lack of job opportunities in the desired field after earning the license could be another reason. The last presumed reason for the number of active APNs not increasing could be that there is no financial compensation nor changes in the given tasks [4].

Since there has not been a detailed investigation into the activities of all the hospice APNs, it is difficult to ascertain where they work and what they are doing. Based on the survey result from the overall APNs, however, if we presume that fewer than 20\% of certified hospice APNs are actively working in the field, the number of active hospice APNs would be estimated to be around 120 nationwide. There are currently 179 specialized hospice care facilities providing various service types in South Korea, including 68 inpatient hospice programs, 39 home hospice programs, 33 pilot consultation hospice programs, 11 hospice programs in long-term care hospitals, and 9 pediatric and adolescent palliative care programs. In other words, it is predicted that less than one hospice APN is present per program. Moreover, since the distribution of certified APNs is regionally biased, it is difficult to realistically implement effective hospice APN policies to properly place APNs at facilities in need. Reflecting this imbalance in the supply and demand of hospice APNs, in the home hospice and the consultation hospice pilot project, which started in 2016 and 2017, the criteria for the placement of nurses for home hospices were determined as hospice or family-medicine APNs, and those for consultation hospices were hospice or oncology APNs, or nurses with 2 years or more experience in hospice work. These placement criteria were adopted due to the shortage in the supply of hospice APNs. This decision reflects the difficulty in supplying a sufficient number of APNs to hospice facilities, even after including APNs from other fields [13].

Specialized hospice care facilities are expanding, and HPC has diversified its types to in-patient, consultation-based, and home hospices. However, the usage of hospice for terminal patients has not yet reached 25\%; this underscores the need to increase the number of hospice training institutions and human resources that meet the standard of law [14]. In order to ensure the quality of hospice care and patients' safety, along with the quantitative expansion of HPC, it is desirable to have at least one hospice APN per facility, who has completed the advanced curriculum, has professional knowledge, and is technically competent [15]. From this perspective, the current supply and demand situation of the hospice APN workforce must be improved.

\section{The role of hospice APNs in South Korea}

Since the first APN was produced in 2005, APNs have steadily broadened their SOP along with medical and social environment changes, such as the specialization of medical fields, medical residency shortages in certain departments, and the expansion of rights of patients as consumers [4]. At the same time, concerns regarding the unclear SOP of APNs and conflicts among different disciplines have grown. With the efforts of professional nursing organizations, in March 2018, it was stipulated in the amended Medical Service Act that the SOP should be determined by the Ordinance of the Ministry of Health and Welfare, and efforts to establish legal grounds for the APN's SOP have been accelerated thereafter. Unfortunately, however, agreement among disciplines and related organizations on APNs' SOP has been delayed, and due to the COVID-19 pandemic situation on top of it, the stipulated SOP that should have been enforced on March 28, 2020 is still pending as of January 2021. Now that it has been established 
that APNs' SOP is to be stipulated by law, it is expected that the discussions will resume, and an agreement will eventually be reached.

One of the factors contributing to confusion in the discussion of APNs' SOP is that the duties of registered nurses and those of APNs are not clearly differentiated. Both APNs and registered nurses (a) perform nursing through the same process of assessment, diagnosis, planning, and evaluation; (b) educate and counsel patients and their families; (c) participate in quality improvement activity, and (d) collaborate with other medical team members. What distinguishes APNs from registered nurses is that APNs provide an advanced level of nursing with experience and qualifications beyond the level of registered nurses. In addition to clinical practice, education, administration, research, and communication skills are reinforced in APNs. The International Council of Nurses (ICN) clarifies this point in their APN competency framework proposed in 2008 [16]. For instance, when assessing subjects, registered nurses should collect both subjective and objective data accurately through a systematic health assessment. APNs receive additional education and training to enhance their clinical reasoning capabilities. Thus, in addition to registered nurse duties, they perform additional tasks (e.g., prescribing relevant diagnostic tests) within the scope permitted by regulations. More specifically, in a HPC setting, general nurses conduct risk assessments for all bereaved families, whereas APNs should select high-risk bereaved families and establish nursing plans accordingly.

Based on the framework regarding APNs' roles and competencies suggested by the ICN, the KABONE suggested the following roles for Korean APNs: advanced nursing practice providers, educators, counsellors, researchers, leaders, and $\mathrm{CO}^{-}$ ordinators/collaborators [9]. The KABONE further proposed a task guideline for APNs in 13 specialties, including nine types of duties, tasks for each duty, and task elements that construct each task [9]. According to the list of tasks for hospice APNs, their nine duties are data collection, clinical decision-making, treatment and intervention, emergency symptom management, education and counseling, environment and resource management, participation in professional development, coordination, and collaboration, which are identical to those of other APN fields. The task elements include several specific characteris- tics of HPC, such as risk assessment of bereaved families, pain management, and end-of-life nursing. This guideline has been used as the basis for APN curriculum and licensing examination criteria. However, this guideline does not accurately reflect all the roles of APNs in other specialized fields such as public health, infection control, health science, and anesthesiology. In addition, the guideline does not describe APNs' actual tasks in specific terms. Thus, there is a limitation in including APNs' nursing practice in the reimbursement system.

The placement criteria of hospice APNs are specified in the enforcement regulation for home and consultation hospices, yet no regulations exist regarding hospice APNs' SOP. In order to prepare a regulation (draft) for the SOP of APNs to be included in the Ordinance of the Ministry of Health and Welfare, the KNA [17] surveyed a panel of 17 hospice APNs to investigate the tasks they are conducting or need to conduct. The KNA collected and analyzed 462 statements, and test validity was evaluated using the Delphi method. The results showed that hospice APNs perform 88 roles in total, which can be categorized into four main types (education, leadership, advanced nursing practice, collaboration and coordination of care) and 23 sub-categories (Table 2). The study conducted by the KNA is valuable since it empirically confirmed hospice APNs perform tasks (e.g., spiritual nursing, end-of-life nursing, and managing patient in transition to hospice care) that are markedly distinct from those of APNs in other fields. Since the other identified roles (e.g., developing and operating family education programs, calculating and analyzing statistics on HPC quality indicators, establishing the goals of care and care plan of patients and their families) from this study are very specific and detailed, the findings provide guidance on what competencies should be trained and evaluated in the future hospice APN curriculum and the licensing examination.

In November 2019, based on many suggestions from various organizations for the SOP regulation of APNs, the Board of Directors of the Korean Society for Hospice and Palliative Care agreed upon the following roles of hospice APNs:

- Providing a multi-dimensional and comprehensive assessment including values and preferences for terminal patients with life-threatening diseases and their families

- Establishing the goals of holistic care and a care plan, and evaluating and coordinating the care plan for terminal pa- 
tients and their families

- Supporting ethical decision-making for terminal patients and their families

- Selecting and managing high-risk bereaved families

- Assessing spiritual needs and providing spiritual counseling for terminal patients and their families

- Managing patients in the transition to HPC

- Providing end-of-life assessment and care
- Providing palliative nursing care to relieve pain and physical symptoms

- Selecting medicine and controlling doses to relieve pain and physical symptoms for the purpose of palliative nursing (under the supervision of physicians)

Among the duties for terminal patients and their families, the following require participation and agreement not only on the part of the interdisciplinary medical team, but also the patients

Table 2. The Roles of Hospice APNs.

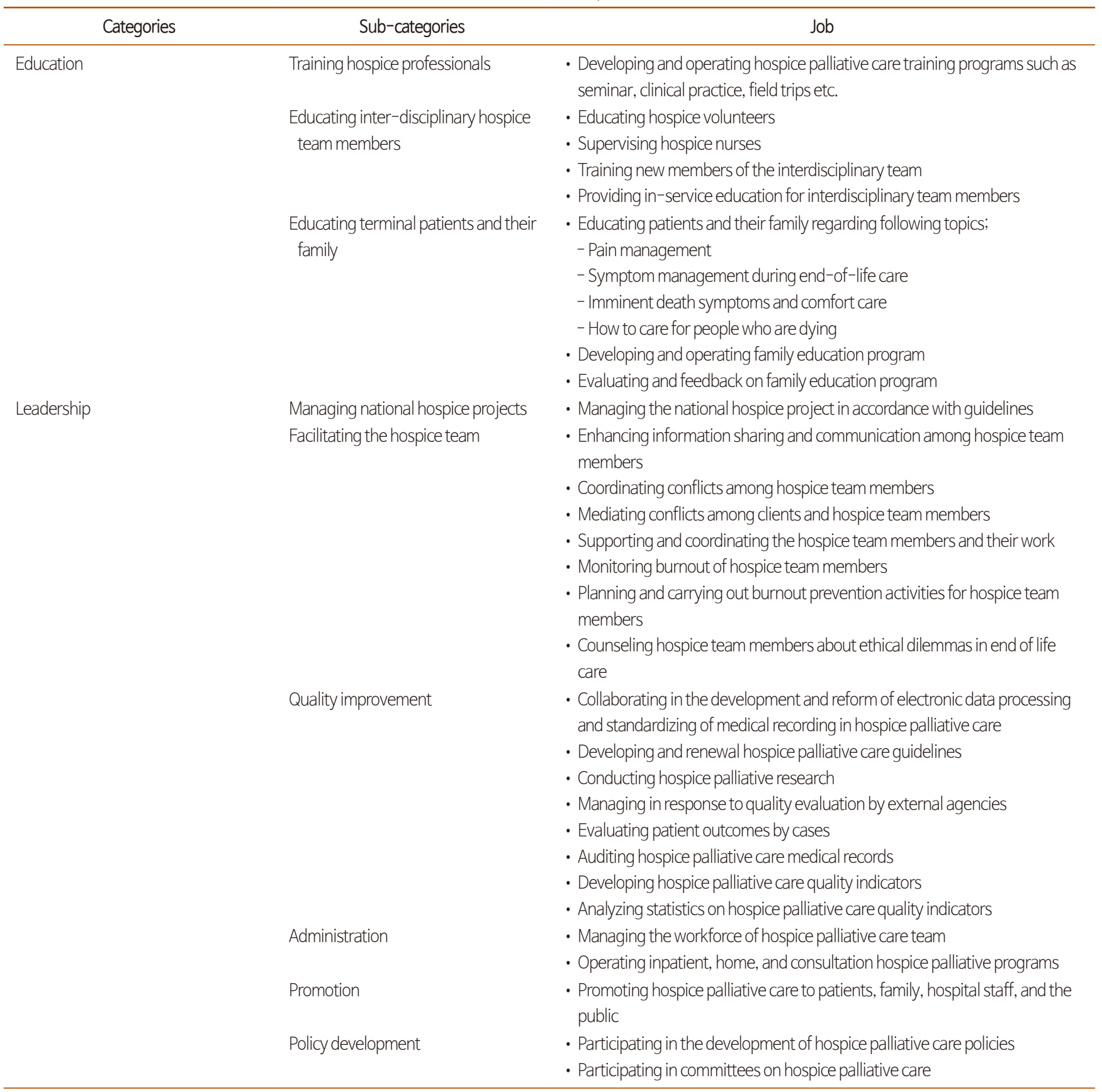


Table 2. Continued 1.

\begin{tabular}{|c|c|c|}
\hline Categories & Sub-categories & Job \\
\hline \multirow[t]{10}{*}{ Advanced nursing practice } & Comprehensive assessment & $\begin{array}{l}\text { - Performing hospice initial assessment including following areas of patients } \\
\text { and their family; } \\
\text { - Complete history taking } \\
\text { - Systematic physical examination } \\
\text { - Values and preferences in end-of-life care } \\
\text { - Holistic care needs } \\
\text { - Emergency symptoms } \\
\text { - Recording the results of comprehensive assessments }\end{array}$ \\
\hline & $\begin{array}{l}\text { Patient-centered care: case } \\
\text { management }\end{array}$ & $\begin{array}{l}\text { - Coordinating resources needed for the patient in an efficient manner } \\
\text { - Supporting the shared decision-making process for patients and their } \\
\text { family } \\
\text { - Establishing the goal of care and a care plan consistent with patient' values } \\
\text { and preferences } \\
\text { - Planning admission and discharge } \\
\text { - Communicatingwith patients and their families about the changes in } \\
\text { treatment } \\
\text { - Evaluating and adjusting the hospice care plan } \\
\text { - Establishing an emergency symptom management plan } \\
\text { - Evaluating achievement of goals of care for the patient } \\
\text { - Consulting on an advance directives with patients and their families }\end{array}$ \\
\hline & Bereavement care & $\begin{array}{l}\text { - Screening high-risk individuals for bereavement } \\
\text { - Assessing needs of bereaved family } \\
\text { - Setting individualized goals for bereaved family } \\
\text { - Developing and operating bereavement programs } \\
\text { - Evaluating outcomes of bereavement programs }\end{array}$ \\
\hline & Counseling & $\begin{array}{l}\text { - Providing supportive counseling to dying patients } \\
\text { - Providing supportive counseling to family members of dying patients } \\
\text { - Evaluating needs for family meetings } \\
\text { - Hosting family meetings }\end{array}$ \\
\hline & Spiritual care & $\begin{array}{l}\text { - Assessing spiritual needs } \\
\text { - Providing spiritual counseling } \\
\text { - Referring spiritual care specialists }\end{array}$ \\
\hline & Clinical judgement & $\begin{array}{l}\text { - Adjusting oxygen therapy and wound care plan according to guidelines or } \\
\text { standing orders } \\
\text { - Arranging room allocation based on patients' condition }\end{array}$ \\
\hline & Comfort care in imminent death & $\begin{array}{l}\text { - Acknowledging impending death } \\
\text { - Assessing the comprehensive needs of dying patients and their family } \\
\text { - Managing physical symptoms of dying patients } \\
\text { - Supporting ethical decision-making during dying process } \\
\text { - Provide supportive counseling to family of dying patients }\end{array}$ \\
\hline & $\begin{array}{l}\text { Care in transition to hospice } \\
\text { palliative care }\end{array}$ & $\begin{array}{l}\text { - Providing initial and discharge counselling } \\
\text { - Counseling for home hospice registration } \\
\text { - Assessing discharge suitability } \\
\text { - Following up patients after discharge } \\
\text { - Sharing patient care plan and collaborating with other health care teams }\end{array}$ \\
\hline & Treatment skills & - Inserting naso-gastric tube \\
\hline & Program management & $\begin{array}{l}\text { - Developing and managing programs to improve quality of life of patients } \\
\text { and their family }\end{array}$ \\
\hline
\end{tabular}


Table 2. Continued 2.

\begin{tabular}{|c|c|c|}
\hline Categories & Sub-categories & Job \\
\hline \multirow[t]{5}{*}{$\begin{array}{l}\text { Collaboration } \\
\text { and coordination of care }\end{array}$} & Collaboration & $\begin{array}{l}\text { - Establishing a collaboration system for hospice palliative care within the } \\
\text { community }\end{array}$ \\
\hline & Consultation & $\begin{array}{l}\text { - Providing consultation regarding the process of withholding and } \\
\text { withdrawing life sustaining treatment } \\
\text { - Providing information about hospice palliative care } \\
\text { - Providing consultation regarding symptom management in end of life care } \\
\text { - Advising nurses on care for difficult cases }\end{array}$ \\
\hline & Referral & - Discussing care plan with professionals in other specialties \\
\hline & & $\begin{array}{l}\text { - Facilitating consultation on withholding and withdrawing life sustaining } \\
\text { treatment } \\
\text { - Collaborating with the referral hospice agency } \\
\text { - Referral to social work team, therapists, clinical pastors according to clients' } \\
\text { needs }\end{array}$ \\
\hline & Collaborative case management & $\begin{array}{l}\text { - Providing care to patients and their families through consultation- and/or } \\
\text { home-based hospice palliative care }\end{array}$ \\
\hline
\end{tabular}

APNs: advanced practice nurses.

Source: Korean Nurses Association. A study to prepare regulations for the scope of practice of advanced practice nurses. Seoul:Korean Nurses Association;2018.

Table was reproduced with permission from Korean Nurses Association and the representative author (Soon-Rim Suh).

and their families: establishing the goal of holistic care and a care plan, evaluating, and coordinating care. This is because from the perspective of HPC, the goal and care plan of holistic care goes beyond medical treatment and physical care, further including psychosocial care, and spiritual care plans. During this process, hospice APNs (under the supervision of a physician) need to conduct preliminary counseling of patients and their families, perform a holistic assessment, conduct and coordinate weekly interdisciplinary team conferences, and perform effective and efficient communication among team members.

HPC involves holistic care provided by an interdisciplinary team to improve the quality of life of patients with life-threatening diseases and their families. Therefore, all stages of care should involve physicians, nurses, social workers, and spiritual caregivers from the beginning of the goal-setting and planning stage. Among these members, hospice APNs are professionals who help patients to maintain the best quality of life in the midst of progressing disease through patient-centered care, pain and symptom management, and sympathetic end-oflife nursing care [18]. Just like pouring water into a bowl that contains large and small pebbles, hospice APNs with their new professional identity fill the gaps among disciplines and services within the interdisciplinary team [19]. Although the stan- dards of HPC presented in the National Quality Forum in the United States reflect the goal of an interdisciplinary team, these standards are consistent with the goal of comprehensive and holistic nursing care, and therefore they are particularly suitable for nurses. In 2006, to ensure that high-quality HPC can be provided in all nursing fields, the Hospice Palliative Nurse Association in the US issued a statement that HPC education should be included in the curriculum for APNs in all fields, and that hospice APNs should serve as mentors of these nurses [20]. It is noteworthy that the KNA [17] included fostering the hospice workforce and providing advising as part of hospice APNs' roles because it allows hospice APNs to contribute to expanding human resources capable of providing HPC in all nursing fields. It is also encouraging that the KSHPC, where all interdisciplinary team members recognized and supported the roles and duties of hospice APNs.

\section{Prospects}

\section{1) Establishing regulations on the SOP and standards for work placement}

The amended Article 78, paragraph 3 of Medical Service Act states that APNs "shall conduct the duty of nursing in the relevant area for which his/her qualification is accredited pursuant to paragraph 2." Article 78, paragraph 4 states that 
"the classification of qualifications, standards for qualification, qualification examinations, certificates of qualification, and scope of duties of specialized nurses, and other necessary matters shall be prescribed by Ordinance of the Ministry of Health and Welfare." However, the statutes regarding APN qualification certification do not clearly include APNs' SOP as of January 2021. The absence of legal ground for APNs' role may cause confusion in performing APNs' duties [21]. On June 4, 2019, the Ministry of Health and Welfare hosted the first Consultative Body to Discuss the SOP of the Medical Workforce, and the Korean Medical Association (2 medical specialists), KNA (2 nurses), Korean Hospital Association (2 medical specialists), Korean Intern Resident Association (2 residents), Korean Academy of Medical Sciences (2 medical specialists), and HNA (2 nurses) have started discussing the issues related to SOP. These discussions are still in progress. The Korean Association of Advanced Practice Nurses was also established in 2015 as the central association for APNs. This organization is striving to establish the SOP that effectively reflects the APNs' actual duties that ensure the right to health of the people in the medical field and efficiently fill medical gaps [22]. Through these efforts, these organizations with different opinions are expected to reach an agreement shortly and propose enforcement regulations with detailed description of APNs' duties in each field as suggested by the KNA [17].

Since the interdisciplinary team approach is a distinctive characteristic of HPC, the role of hospice APNs is important when collaborating with various medical specialists. Moreover, particular recognition should be given to the work of consultation and home hospice APNs, as they are responsible for educating and counseling patients in transition and their families. When hospice APNs are working in a special situation such as in patients' homes, where immediate collaboration with other medical professionals is not easy, hospice APNs need to have more autonomy in making clinical decisions based on their training, so that they can promptly control pain or symptoms or satisfy dying patients' physical or psychological needs. For example, legal safeguards should be provided to enable prompt responses through protocols or standard prescriptions for specific situations. In several countries such as the United States, the United Kingdom, and Canada, APNs are authorized to make autonomous decisions regarding treatment and prescriptions [23]. According to the Medical Service Act in Korea, nurses can administer medicine to patients under the prescription of physicians, oriental medical doctors, or dentists, as this is categorized as medical assistance. However, under the Occupational Safety and Health Act [24], as public health managers, nurses can independently administer medicine to prevent disease exacerbation of workers in a workplace. Public civil servants serving as community health practitioners, pursuant to the Act on Special Measures for Health and Medical Services in Agricultural and Fishing Villages, may engage in minor medical practices prescribed by a presidential decree in the medically underserved areas designated as their work areas [25].

Any nursing facilities that conduct infection prevention and control activities by hiring at least one infection control APN or a designated nurse who has completed a 1-year training program are granted reimbursements, and they are calculated once per day of patient's admission to the hospital. To meet the reimbursement requirement, infection control APNs are hired at most medical institutions [21]. Similarly, to realize universal HPC, a legal ground should be established to assign hospice APNs to work as HPC coordinators at every medical institution. Establishing criteria for hiring hospice APNs as evaluation indices for the accreditation of medical institutions could also secure APN placement. Based on whether a hospice APN is hired by a hospice specialized facility, 3 points are added to the maximum of 50 points of operating performance [26]. However, the new evaluation criteria need to encompass not only the hiring status of APNs, but also on whether they are actually performing the duties of hospice APNs.

Reviewing the statutes focusing on nurses, midwives, APNs, assistant nurses, Kim et al. [21] indicated that the interpretations are not consistent due to the sporadic statutes, and this inconsistency may lead to confusion in the actual performance of nursing duties; therefore, the enactment of a nursing law integrating the scattered nursing-related statutes should be considered to improve the consistency of laws related to duties of nursing. If the nursing law promoted by KNA is enacted, the legal basis for the duties of APNs will also become clearer in the future. 


\section{2) Curriculum reorganization}

APNs are working in 13 areas in Korea, and their SOP is not clearly distinguished, causing many overlapping areas in their educational curriculum and core competencies. It was also found that the compensation of APNs is unsatisfactory, while the academic workload is greater than that of other master's degree programs, which decreases the motivation to apply to APN programs. Accordingly, several practical efforts to revise the curriculum seem necessary, including: (a) reducing the $\mathrm{ex}^{-}$ cessive academic burden by integrating subjects; (b) reducing training hours to a realistic level; and (c) benchmarking residency trainings and licensing examinations, so that the training content and the licensing examination can be better adjusted to match practice in clinical settings.

In the United States, advanced practice registered nurses (APRNs) are required to have a masters' degree or above and are divided into four different categories: certified registered nurse anesthetist (CRNA), certified nurse midwife (CNM), clinical nurse specialist (CNS), and certified nurse practitioner (CNP). The certification is given to masters' degree holders based on their years of experience in the clinical field [27]. Although the APRN license is broadly divided into four categories reflecting the characteristics of the clinical practice fields that are more subdivided and specialized, each subfield is specified to reflect the expertise in each field. Along with this trend, the KNA [17] also suggested that 13 APN areas should be reduced to four areas integrating similar duties: special field nursing, public health, acute critical care, and chronic or terminal care. In other words, the system should be reorganized to deploy APN professionals effectively.

\section{3) Developing a system to understand APN licensing status including continuing education}

Registered nurses are obligated to report their licensing and employment status every 3 years, and it is handled by the KNA entrusted by the Ministry of Health and Welfare. However, APNs are not required to report their licensing or employment status, and there is no regulation on continuing education; they only need to provide information about their licensing status and complete 8 hours or more of continuing education every year as a registered nurse. Since they are not legally required to report their licensing or employment status, it makes it difficult to identify APNs' current working status [21]. In Canada, there are APNs for families, adult health, and pediatric health, and they are provided with continuing education and support to be able to continue providing HPC in their field [28]. Categorizing and providing APNs' continuing education based on their core competencies according to each experience level would enable more specialized patient management. In other words, in order to improve the quality of life of terminal patients and their families and to develop specialized hospice nursing practice, developing a clear continuing education program is necessary.

\section{4) Developing health insurance fees for APN practice}

APNs demonstrate excellent patient outcomes and are potentially cost-effective $[29,30]$. Under the National Health Insurance System in South Korea, however, hospice nursing fees are only compensated indirectly through the differential payment of nursing management fees, and APNs' practice is not recognized independently. The nursing fees of family medicine APNs are paid by health insurance under their own legally recognized fee system. As education fees for cancer patients have been established, oncology APNs have been integrated relatively early into clinical practice compared to those in other fields, and the number of oncology APNs has been increasing every year. Unfortunately, this is not the case for hospice APNs. Specific efforts should be made to develop an appropriate insurance reimbursement system, such as establishing a separate fee for APNs' nursing practices or establishing a fee system that adds a certain percentage to existing hospitalization fees, observation fees, or management fees. To make this systematic change possible, it is necessary to regularly provide evidence of the achievements of hospice APNs' nursing practices, such as reduction of pain and symptoms of terminal patients, reduction of family care burdens, and improvement of quality of life and care satisfaction.

\section{CONCLUSION}

In order to vitalize the hospice APN system, this study reviewed hospice APNs' educational curriculum and domestic and international laws regarding APNs to propose suggestions regarding their roles and SOP, and discussed their future 
prospects. Hospice APNs are professionals at an advanced level who perform comprehensive assessments of physical, psychosocial, and spiritual areas, including pain and symptom relief, thereby improving the quality of life of the terminal and end-of-life patients and their families. Hospice APNs' education is available at 10 universities in the nation, and consists of a master's degree curriculum. Their academic burden is high and the financial compensation after earning a license is insufficient, which hinders prospective trainees from enrolling in APN programs. After the enforcement of the Act on Decisions on Life-Sustaining Treatment, it is desirable to have at least one APN per institution who has proven his or her professional knowledge and technical competence through an advanced curriculum and the licensing examination to ensure high-quality care, patient safety, and the quantitative expansion of HPC; thus, the current workforce shortages of hospice APNs should be improved. Meanwhile, in the field of nursing, the roles of hospice APNs are specifically categorized into education, leadership, advanced nursing practice, and coordination and collaboration. Although the basis for the SOP of APNs is specified in the Medical Service Act, there is no regulation yet on the specific SOP of APNs, and they are only included in the criteria for the placement of home and consultation hospices, which are subject to the Act on Decisions on Life-Sustaining Treatment. Therefore, it is hoped that the role of hospice APNs, suggested in the nursing field, will be legally distinguished from both the role of general hospice nurses and from the role of APNs in other fields. This study also suggests the need to continue efforts to vitalize the APN system; for example, (a) standards for the placement of hospice APNs should be regulated as subordinate statutes; (b) the educational system should be improved through curriculum integration and reduction of the academic burden; (c) continuing education system or a system to check the licensing status of APNs should be developed, and their authority should be enhanced.

\section{CONFLICT OF INTEREST}

No potential conflict of interest relevant to this article was reported.

\section{ORCID}

So-Hi Kwon, https://orcid.org/0000-0002-5640-0463

Myung-Hee Park, https://orcid.org/0000-0002-7256-8151

Hyun Sook Kim, https://orcid.org/0000-0001-7108-0966

\section{AUTHOR'S CONTRIBUTIONS}

Conceptualization: SHK, HSK. Data curation: SHK, MHP, HSK. Funding acquisition: HSK. Methodology: SHK, HSK. Writing - original draft: SHK, MHP, HSK. Writing - review \& editing: SHK, HSK.

\section{SUPPLEMENTARY MATERIALS}

Supplementary materials can be found via https://doi. org/10.14475/jhpc.2021.24.1.1.

\section{REFERENCES}

1. Quill TE, Abernethy AP. Generalist plus specialist palliative care-creating a more sustainable model. N Engl J Med 2013;368:1173-5.

2. Lindley LC, Herr KA, Norton SA. The role of hospice and palliative care nurses in quality improvement. J Hosp Palliat Nurs 2017;19:160-5.

3. The National Law Information Center. Act on hospice and palliative care and decisions on life-sustaining treatment for patients at the end of life [Internet]. Sejong: Ministry of Government Legislation; 2020 [cited 2021 Jan 5]. Available from: https://www.law.go.kr/LSW//IslnfoP.do? IsiSeq=217303\&anc Yd=20200407\&ancNo=17218\&efYd=20200407\&nwJoYnInfo=Y\&efGubun=Y\&chrClsCd=010202\&anc YnC $\mathrm{hk}=0 \# 0000$.

4. Seol M, Shin YA, Lim KC, Leem C, Choi JH, Jeong, JS. Current status and vitalizing strategies of advanced practice nurses in Korea. Perspect Nurs Sci 2017;14:37-44.

5. Korean Association of Advanced Practice Nurses. Korean advanced practice nurse annual report 2019 [Internet]. Seoul: Korean Accreditation Board of Nursing Education; 2020 [cited 2021 Jan 4]. Available from: http://www.kaapn.or.kr/new/sub06/6_1.php? mode=view\&number= 1361 \& page $=1$ \&b_name=data_board.

6. Research Institute for Healthcare Policy. A study on the legal problems and countermeasures for the utilization of medical support staff. 
Seoul: Research Institute for Healthcare Policy; 2011.

7. Kim BH, Choe SO, Chung BY, Yoo YS, Kim HS, Kang A, et al. Job analysis for role identification of general hospice palliative nurse. Korean J Hosp Palliat Care 2010;13:13-23.

8. The National Law Information Center. Medical service act [Internet]. Sejong: Ministry of Government Legislation; 2018 [cited 2021 Jan 5]. Available from: https://www.law.go.kr/LSW//IsInfoP.do? lsiSeq=202805\&chrClsCd=010202\&urlMode=IsInfoP\&efYd=20180921 \&ancYnC $h k=\# 0000$.

9. Korean Accreditation Board of Nursing Education. Definition, role, and qualification exam for advanced practice nurses [Internet]. Seoul: Korean Accreditation Board of Nursing Education; 2004 [cited 2021 Jan 4]. Available from: http://www.kabone.or.kr/kabon04/index03.php.

10. The National Law Information Center. Regulations regarding qualification recognition of professional nurses [Internet]. Sejong: Ministry of Government Legislation; 2017 [cited 2021 Jan 5]. Available from: https://www.law.go.kr/LSW/IsInfoP.do? lsiSeq=192902\&efYd=2017033 0\&ancYnChk=0\#0000.

11. Korean Nurses Association. Current status of Korean advanced practice nurse. Seoul:Korean Nurses Association;2014.

12. Hospital Nurses Association. Survey on the status of hospital nursing staff placement. Seoul:Hospital Nurses Association;2018.

13. The National Law Information Center. Act on hospice and palliative care and decisions on life-sustaining treatment for patients at the end of life. Attachment 1 Criteria for designation of specialized hospice organizations [Internet]. Sejong: Ministry of Government Legislation; 2019 [cited 2021 Jan 5]. Available from: https://www.law.go.kr/LSW//IsInfoP.do? lsiSeq=208190\&chrClsCd=010202\&urlMode=lsinfoP\&efYd=2 0190328\&ancYnChk=0\#0000.

14. National Hospice Center. Current status and statistics [Internet]. Goyang: National Hospice Center; 2021 [cited 2021 Jan 5 ]. Available from: https://hospice.go.kr/pain/stat.do? menu_no=634\&brd_mgrno=.

15. Korea Health Industry Development Institute. Demand and supply planning for the advanced practice nurses [Internet]. Seoul: Korea Health Industry Development Institute; 2004. [cited 2021 Jan 4]. Available from: https://scienceon.kisti.re.kr/srch/selectPORSrchReport. do? cn=TRKO201100002574.

16. International Council of Nurses. ICN framework of competencies for the nurse specialist [Internet]. Switzerland: International Council of Nurses; c2009 [cited 2021 Jan 4]. Available from: https://siga-fsia.ch/files/user_upload/08_ICN_Framework_for_the_nurse_specialist.pdf.

17. Korean Nurses Association. A study to prepare regulations for the scope of practice of advanced practice nurses. Seoul:Korean Nurses Association;2018.

18. George T. Role of the advanced practice nurse in palliative care. Int J Palliat Nurs 2016;22:137-40.

19. Kennedy C, Brooks Young P, Nicol J, Campbell K, Gray Brunton C. Fluid role boundaries: exploring the contribution of the advanced nurse practitioner to multi-professional palliative care. J Clin Nurs 2015;24:3296-305.

20. Hospice Palliative Nurses Association. HPNA position paper; value of Advanced Practice Nurse in Palliative Care. J Hosp Palliat Nurs 2007:9:72-3.

21. Kim M, Kim I. Lee Y. A study on legal coherence of legislations related to nursing services: focusing on registered nurse, midwife, advanced practice nurse and nurse assistant. Health Soc Welfare Rev 2018;38:420-57.

22. Korean Association of Advanced Practice Nurses. Notice. Position statement, request to the consultation group for medical professionals' scope of practice [Internet]. Seoul: KAAPN; 2019 [cited 2021 Jan 4]. Available from: http://www.kaapn.or.kr/new/sub04/4_1.php? mode=v iew\&number=1311\&page=1\&b_name=notice_board.

23. International Advanced Practice Nursing. The role of advanced practice nursing internationally [Internet]. London: International Advanced Practice Nursing [cited 2020 Aug 9]. Available from: https://internationalapn.org/2013/10/07/united-kingdom.

24. The National Law Information Center. Occupational safety and health act [Internet]. Sejong: Ministry of Government Legislation; 2016 [cited 2021 Jan 5]. Available from: https://www.law.go.kr/LSW//IsInfoP.do? IsiSeq=218289\&chrClsCd=010202\&urlMode=IsInfoP\&efYd=202101 $16 \&$ anc YnChk=0\#0000.

25. The National Law Information Center. Act on the special measures for public health and medical services in agricultural and fishing villages, etc [Internet]. Sejong: Ministry of Government Legislation; 2016 [cited 2021 Jan 5]. Available from: https://www.law.go.kr/LSW//IsInfoP. do? lsiSeq=183551 \& chrClsCd=010202\& urlMode=IsInfoP\&efYd=20161130\&ancYnChk=0\#0000.

26. Republic of Korea policy briefing: policy database [Internet]. 2019 hospice palliative service operation guidelines. Sejong: Ministry of Culture, Sports and Tourism; 2019 [cited 2021 Jan 5]. Available from: https://www.korea.kr/archive/expDocView.do? docld=38675.

27. International Council of Nurse. ICN nurse practitioner/advanced practice nursing network [Internet]. Geneve: International Council of Nurse; 2020 [cited 2021 Jan 5]. Available from: https://international.aanp.org.

28. Collins CM, Small SP. The nurse practitioner role is ideally suited for palliative care practice: A qualitative descriptive study. Can Oncol Nurs J 2019;29:4-9.

29. Martin-Misener R, Harbman P, Donald F, Reid K, Kilpatrick K, Carter N, et al. Cost-effectiveness of nurse practitioners in primary and specialised ambulatory care: systematic review. BMJ Open 2015;5:e007167.

30. Kilpatrick K, Reid K, Carter N, Donald F, Bryant-Lukosius D, Martin-Misener R, Kaasalainen S, et al. A systematic review of the cost-effectiveness of clinical nurse specialists and nurse practitioners in inpatient roles. Nurs Leadersh (Tor Ont) 2015;28:56-76. 